\title{
Validation of the two minute step test for diagnosis of the functional capacity of hypertensive elderly persons
}

\section{Abstract}

Objectives: To analyze the accuracy of the 2 minute step test in the diagnosis of the normal functional capacity (FC) of hypertensive elderly individuals or hypertensive elderly individuals with other associated chronic conditions (ACC). Methods: An observational diagnosis type study of 101 subjects, 41 of whom were hypertensive and 60 of whom were normotensive, was carried out. Receiver Operating Characteristic curves (ROC) were constructed based on the normal FC variable. Results: For hypertensive patients, the 2MST, with an under the ROC curve area of 0.7 (95\% CI: 0.50 to $0.87, \mathrm{p}=0.04)$, proved to be accurate at diagnosing FC. Among hypertensive individuals with an elevation of 69 , sensitivity of $80 \%$ and specificity of $54 \%$ were observed. The 2 MST was accurate at predicting normal FC among hypertensive patients with ACC, with an under the ROC curve area of 0.88 (95\% CI: 0.69 to $1.00, p=0.02)$. With an elevation of 65 the sensitivity was $83 \%$ and the specificity was $67 \%$. Conclusions: The 2 MST revealed good sensitivity and specificity when assessing the FC of elderly hypertensive individuals and elderly hypertensive patients with ACC, which was not the case among normotensive elderly persons.

\footnotetext{
Universidade Federal do Rio Grande do Norte, Departamento de Saúde Coletiva, Programa de Pósgraduação em Saúde Coletiva. Natal, RN, Brasil

2 Universidade Federal do Rio Grande do Norte, Faculdade de Ciências da Saúde do Trairi, Santa Cruz, RN, Brasil.

3 Faculdade Maurício de Nassau, Curso de Fisioterapia. Natal, RN, Brasil.

4 Faculdade de Ciências Médicas de Minas Gerais, Curso de Medicina. Belo Horizonte, MG, Brasil.

5 Universidade Federal do Rio Grande do Norte, Faculdade de Ciências da Saúde do Trairi, Curso de Fisioterapia. Santa Cruz, RN, Brasil.
}

Key words: Validation Studies; Elderly; Hipertension. 


\section{INTRODUCTION}

The data generated by assessments of functional capacity (FC) improve our understanding of the profile of elderly individuals, with a view to delaying or preventing disabilities. ${ }^{1}$ Activities of daily living (ADLs), instrumental activities of daily living (IADL) and functional mobility (FM) are the most frequently used measurements to assess the functional capacity of an individual. ${ }^{2}$ However, the assessment of $\mathrm{FC}$ using practical tests of functional performance provides only a basic analysis of FM, creating a need for studies that validate these practical tests with different instruments that also assess other aspects, including ADLs.

In this context, there is a correlation between chronic diseases, particularly systemic hypertension (SH), and functional capacity (FC). High blood pressure, as well as its associated chronic conditions, can lead to low levels of FC and have a direct effect on the quality of life of elderly individuals..$^{3-5}$

Validated and easy-to-apply instruments are important when assessing elderly individuals, either in research projects or in the daily clinical practice of health professionals. Significantly, they also reduce the information and memory bias that is inherent to many questionnaires.

The two-minute step test (2MST) involves advantages related to the practicality and speed of its application, as well as its easy reproducibility and the small space required to perform the test. The 2MST can be used instead of other performance tests that are more difficult to apply, including the timed up and go test or the 6-minute walk test. ${ }^{6}$ Until now, studies that address the validation of the 2MST for the Brazilian population have been scarce, ${ }^{6,7}$ particularly for hypertensive elderly individuals with associated chronic conditions (a sedentary lifestyle, an elevated BMI or other chronic diseases).
Therefore, the aim of the present study was to analyze the accuracy of the 2MST when diagnosing normal FC among normotensive elderly individuals, hypertensive elderly individuals with no associated chronic conditions and hypertensive elderly individuals with associated chronic conditions.

\section{METHODS}

The present study is part of the project "Blood pressure and functional capacity in the elderly" and was approved by the relevant Research Ethics Committee under protocol number 010/2011. It deals with diagnostic validity and has a crosssectional design. The sample (106 elderly individuals) was non-probabilistic and was selected based on convenience. All of the participants signed a free and informed consent form.

The assessments were carried out between January and March 2011. The volunteers were approached while waiting to be seen in a medical center or during random visits to their homes in Belo Horizonte. The visits were conducted in residential buildings in a neighborhood in the center of the city. The presence of elderly individuals in the building was determined, followed by their interest in participating in the research. The household sample was significant in terms of reducing the possibility of selection bias.

Based on the application of the inclusion and exclusion criteria, 101 subjects participated fully in the study, during which the following variables were analyzed: blood pressure (BP); the 2MST; the Katz index; the practice of physical activity; the presence of other chronic diseases and the BMI. In total, there were 41 hypertensive individuals (blood pressure $>139 / 89 \mathrm{mmHg}$ ) and 60 normotensive individuals (blood pressure $<140 / 90 \mathrm{mmHg}$ ). A casual measurement parameter was adopted. ${ }^{8}$ The main inclusion criteria were as follows: appropriate 
age; able to perform the proposed tests without great risks; able to understand the questionnaires. The main exclusion criteria were as follows: a high risk of falls and a lack of collaboration in relation to the questionnaires. All of the criteria are listed below:

Inclusion criteria: aged 60 years or more; no cardiovascular diseases that would limit the performance of the proposed tests; no respiratory diseases that would limit the performance of the proposed tests; no clinical diagnosis of neurological diseases that could affect the cognitive levels of individuals. Exclusion criteria: significant vestibular disorders that could lead to a risk of falls; a high potential risk of falls (history of three or more falls in the previous year, leading to fractures); not responding to all of the proposed questions.

Research instruments: (a) the two-minute step test (2MST) - to measure the number of elevations, one knee was chosen as a reference. The maximum number of elevations of the knee that the individual could perform in two minutes was recorded. When a signal was given, the participant began the minute step (without running). The minimum height of the knee was set at a mean point between the patella and the anterosuperior iliac spine, ${ }^{7,9}$ (b) the Kats Index for ADLs - the Katz index has been validated, perfected and transculturally adapted for Brazilian Portuguese. This questionnaire consists of six questions that assess independence in the performance of different activities of daily living and as such, it is more than just a simple assessment of mobility as the only criteria of functional capacity. The score is based on the sum of all positive responses for independence, where a score of 0 indicates complete independence and a score of 6 points indicates complete dependence during ADLs. ${ }^{10,11}$ In the present study, a score above zero was considered a functional disability.
Statistical analysis: the data was analyzed descriptively using mean and standard deviation values for the continuous variables and percentage values for categorical variables. In order to establish the validity of the minute step test in relation to the Katz index, Receiver Operating Characteristic (ROC) curves were created, using functional capacity as a state variable. The validity was estimated by stratifying normotensive and hypertensive individuals, considering physical activity, the body mass index and the presence of chronic conditions associated with hypertension. The level of significance was set at $5 \%$ to minimize type I errors. Version 20.0 of SPSS ${ }^{\circledR}$ software (IBM) was used.

\section{RESULTS AND DISCUSSION}

The age of the individuals in the sample ranged from 60 to 89 years, with a mean age of 69.80 (SD \pm 7.55). Of these, $73(72.3 \%)$ were women. Hypertension was confirmed in $41(40.6 \%)$ of the individuals, while $54(53.5 \%)$ were overweight/ obese and 64 (63.4\%) suffered from another associated chronic disease. Overweight/obese individuals were slightly more common among those with hypertension $(63.4 \%)$. In total, $82.9 \%$ of the hypertensive participants were sedentary and of these, $65.9 \%$ suffered from an associated chronic condition. The results of the 2MST were better among normotensive participants (mean $=88.68$, $\mathrm{SD} \pm 24.63)$ than among hypertensive participants (mean $=78.41, \mathrm{SD} \pm 25.78$ ).

Concerning the accuracy of the 2MST in terms of diagnosing normal FC, it was found that the area under the ROC curve was 0.61 (CI95:0.42 to $0.75 ; \mathrm{p}=0.12$ ) for normotensive individuals, which did not enable us to distinguish (beyond chance) individuals with functional disabilities (Figure 1A). Conversely, among the hypertensive elderly individuals, the minute step test confirmed an area 
under the ROC curve of 0.7 (CI95\%:0.50 to 0.87; $\mathrm{p}=0.04)$, thereby demonstrating validity in terms of diagnosing FC (Figure 1B).

For hypertensive elderly individuals, it was found that 69 elevations was an excellent cutoff point when seeking to identify normal functional capacity, providing a sensitivity value of $80 \%(0.80)$ and a specificity value of 54\% (0.46). If a lower cutoff point was used, the diagnostic test would be more sensitive and ideal for tracking. The opposite is also true for specificity, in that a higher cutoff point would make the test more specific.

Considering other factors such as AF, high BMI and associated chronic diseases, Figure 1C shows that the 2MST did not provide an accurate diagnosis of normal FC among normotensive individuals (area $=0.59$; CI95: 0.30 to $0.87 ; \mathrm{p}=0.52$ ). Conversely, among hypertensive elderly individuals with associated chronic conditions, the validity of the 2MST, in terms of predicting normal FC, was confirmed, given that the area under the ROC curve was 0.88 (CI95\%: 0.69 to $1.00 ; \mathrm{p}=0.02$ ), (Figure 1D).

Between the cutoff points for the diagnosis of normal FC among hypertensive individuals with associated chronic conditions, the ideal cutoff point would be 65 elevations, which provides a sensitivity value of $83 \%$ and a specificity rate of $67 \%$. In cases of more sensitive assessments, a lower quantity of elevations should be used, whereas a greater quantity of elevations should be used when seeking more specificity.

During treatment or rehabilitation, flaws in the functional assessment process used for elderly individuals are common. The functional level may be underestimated by certain health professionals, while others can overestimate functionality, and some may even forget to assess these levels entirely. Accurate tests can reduce malpractice during the assessment process. ${ }^{12}$

When seeking to diagnose a functional disability, the ideal scenario would involve the selection of a cutoff point with high sensitivity, which we were able to do among hypertensive individuals and hypertensive individuals with associated chronic conditions. When seeking to confirm a diagnosis, the ideal scenario would involve the selection of a cutoff point with high specificity. In this case, only the group of hypertensive individuals with associated chronic conditions exhibited satisfactory specificity for the suggested cutoffs. ${ }^{12}$ Therefore, the selection of the most appropriate cutoff point for the criteria of the clinical assessment will depend on the profile of the individual and the objective of the examiner.

Arterial hypertension can have a negative effect on the functional disability of elderly indivisuals. ${ }^{3-5,13}$ Thus, effectively tracking hypertension among the individuals affected could enable an earlier and more specific intervention. 

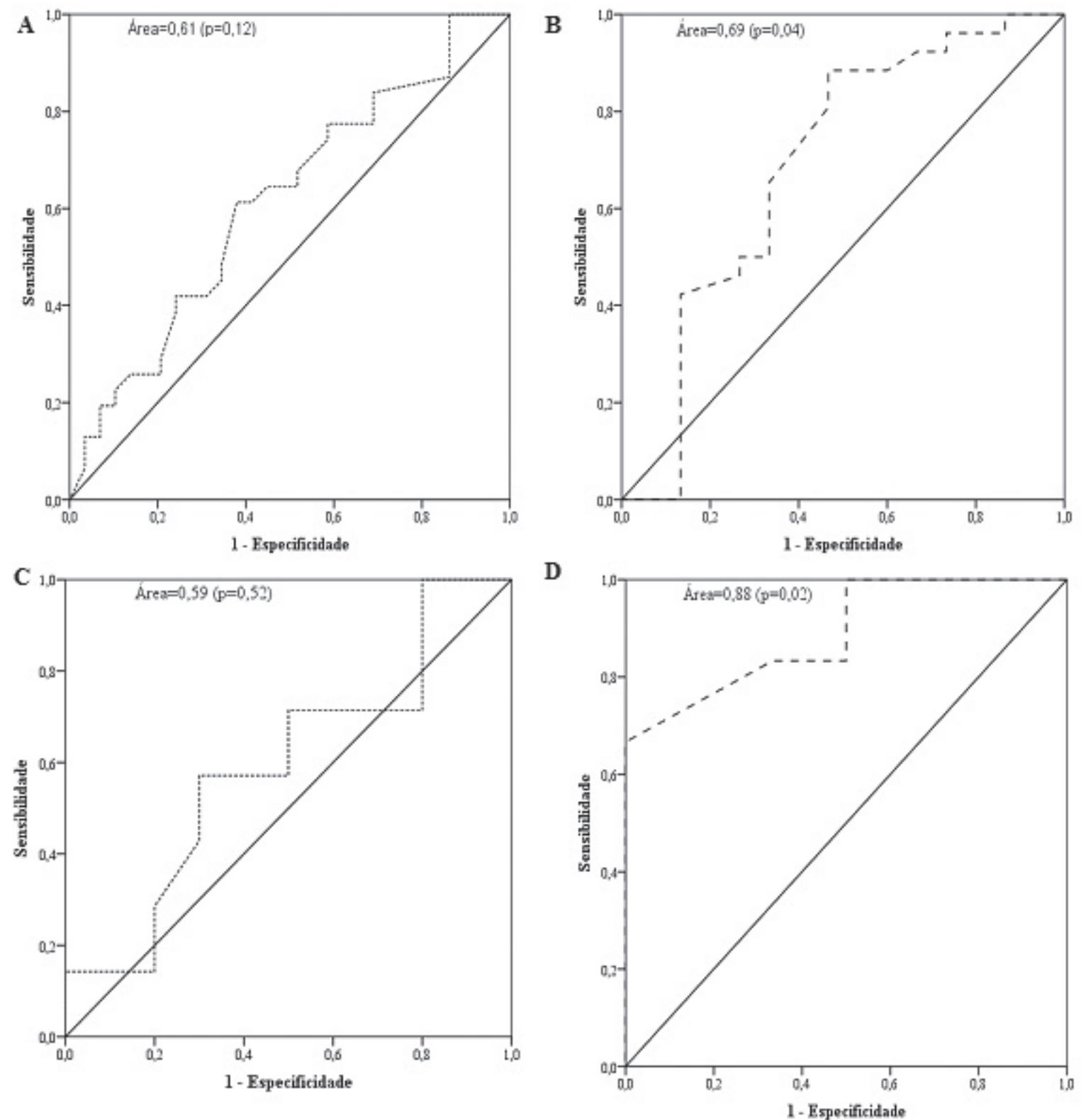

Legend: A - ROC* curve for normotensive individuals (dotted); B - ROC curve for hypertensive individuals (dashed); C - ROC for normotensive, sedentary, overweight/obese individuals with associated chronic diseases; D - ROC curve for hypertensive, sedentary, overweight/obese individuals with associated chronic diseases. *ROC (Receiver Operating Characteristic).

Figure 1. Validity of the minute step test to diagnose functional capacity using the Katz Index as the standard of comparison. Belo Horizonte, 2011. 


\section{CONCLUSIONS}

The 2MST exhibited satisfactory sensitivity and moderate specificity in the assessments of hypertensive elderly individuals, particularly those with associated chronic conditions, a sedentary lifestyle or a high BMI. The cutoff point for this group was 65 elevations. In the hypertensive group, the test only demonstrated a satisfactory sensitivity and specificity when the cutoff point was 69 elevations. The diagnostic validity of the 2MST was not confirmed for normotensive elderly individuals.

Therefore, the 2MST seems to be a valid, fast and inexpensive method of diagnosing functional disabilities in hypertensive elderly individuals. The results are more accurate when the hypertension is accompanied by comorbidities, which is more common in the current population. The 2MST is ideal for clinical outpatient and primary health care contexts.

\section{REFERENCES}

1. Fiedler MM, Peres KG. Capacidade funcional e fatores associados em idosos do Sul do Brasil: um estudo de base populacional. Cad Saúde Pública 2008;24(2):409-15.

2. Paixão CM Júnior, Reicheenheim EM. Uma revisão sobre instrumentos de avaliação do estado funcional do idoso. Cad Saúde Pública 2005;21(1):7-19.

3. Ramos RA, Guimarães FS, Cordovil I, De Sá Ferreira A. The six-minute walk distance is a marker of hemodynamic-related functional capacity in hypertension: a case-control study. Hypertens Res 2014;37(3):746-52.

4. Zattar LC, Boing AF, Giehl MWC, D’orsi E. Prevalência e fatores associados à pressão arterial elevada, seu conhecimento e tratamento em idosos no sul do Brasil. Cad Saúde Pública 2013;29(3):507-21.

5. Hajjar I, Lackland DT, Cupples LA, Lipsitz LA. The association between concurrent and remote blood pressure and disability in older adults. Hypertension 2008;50(6):1026-32.

6. Pedrosa R, Holanda G. Correlação entre os testes da caminhada, marcha estacionária e tug em hipertensas idosas. Rev Bras Fisioter 2009;13(3):252-6.

7. Robortella CN, Rocha SM, Wildner WR, Gorgatti MG. Reprodutibilidade de uma bateria de testes de atividade de vida diária para indivíduos idosos com deficiência visual. Rev Bras Ciênc Mov 2008;16(4):1-21.

8. Sociedade Brasileira de Cardiologia. 6 ${ }^{a}$ Diretrizes Brasileiras de Hipertensão Arterial. Rev Bras Hipertens 2010;17(1):4.

9. Rikli RE, Jones CJ. Development and validation of a functional fitness test for community residing older adults. J Aging Phys Act 1999;7:129-61.

10. Katz S, Ford AB, Moskowitz RW, Jackson BA, Jaffe MW. Studies of illness in the aged. The index of ADL: a standardized measure of biological and psychosocial function. JAMA 1963; 12:914-9.

11. Lino VTS, Pereira SEM, Camacho LAB, Ribeiro ST Filho, Buksman S. Adaptação transcultural da Escala de Independência em Atividades da Vida Diária (Escala de Katz). Cad Saúde Pública 2008; 24(1):103-12.

12. Medronho RA, Perez MA. Testes diagnósticos. In: Medronho RA, Carvalho DM, editores. Epidemiologia. 2 ed. São Paulo: Atheneu; 2009. p. 389-402.

13. Guedes MBOG, Guedes TSR, Ribeiro JM. Correlação entre hipertensão arterial e capacidade funcional de idosos: uma revisão da literatura. Rev APS 2013;6(4):455-9. 